\title{
Sri Lanka - GCC temporary economic migration corridor and the circular migration of Female Domestic Workers
}

\author{
Madhuka Sanjaya Wickramarachchi \\ Ministry of Foreign Affairs \\ Sri Lanka \\ DOI: $10.29322 /$ IJSRP.10.10.2020.p10619 \\ http://dx.doi.org/10.29322/IJSRP.10.10.2020.p10619
}

\begin{abstract}
Sri Lanka-GCC temporary economic migration corridor which boomed in the early 1980s quickly became feminized with increasing number of women moving back and forth as Female Domestic Workers. The recruitment process of Female Domestic Workers in Sri Lanka presents several peculiarities. Apart from well-established push and pull factors of economics, there are a number of mooring factors which forms the migration decision especially in the Female Domestic Workers who follows a circular migration pattern. A survey conducted in 2019 in Kuwait and Saudi Arabia sheds some light on these mooring factors. It provides that monetary gain is the main push and pull factor and factors such as debt free departure, psychosocial assurance through upfront payments, familiarity with destination, personal networks, escapism, socio-cultural traits and negative stereotyping are operate as mooring factors in migration decision. The study underlines that some of the established ideas on female migrant domestic workers cannot be applied in toto to circular Female Domestic Migrant Workers.
\end{abstract}

Index Terms - Sri Lankan female migrant worker, Sri Lanka GCC migration corridor, circular migration, migration agent

\section{INTRODUCTION}

$\mathrm{M}$ igration for economic purposes is a global occurrence and a historical development. From different types of economic migration patterns, the temporary economic migration has become the prevalent and growing trend in the post-world War II era. One of the world's largest outflows of temporary migrant workers are originating from the Asian region heading mainly towards the Member States of the Gulf Cooperation Council (GCC) in the Middle East.

The oil boom in the 1970s in the Arabian states (now referred to as GCC Member States) provided an impetus to jump-start large scale development projects, which required large amount of labour at all levels. The abolition of slavery (1962 in Saudi Arabia and the rest earlier) and radical changes occurred in lifestyles also attracted a segment of workers employed by households for domestic work. At the inception, temporary migrant labour in GCC Member States was sourced from the neighbouring countries and from Africa. By the mid-1980s this trend had changed and the Afro-Arabian labour was swapped for Asian labour. This was an attempt to avoid the spread of radical and socialistic political ideologies, as well as to safeguard the political interests of monarchies in the Gulf. The underlying perception of the Asian workforce was to the effect that politically neutral, docile, flexible, easily monitored and filtered and willing to work at lower wages (Rajan, 2020; Kapiszewski, 2006). The 'open door demographic policy' adopted by the GCC countries, allowed temporary migration without age or skills restrictions. All these factors encouraged large scale Asian migration (Hussain, 2016; Al-Ubaydli, 2015) and thus established the Asia-GCC migration corridor. The absorption of migrant workers into the GCC Member States has been extraordinary, with 90 percent of the population in states such as the State of Qatar consists of temporary non-resident migrant workers (Babar and Gardner, 2016). The Asians, both male and female, who migrated to GCC regions were predominantly low skilled workers, including construction workers, truck drivers, cooks, helpers, office boys, custodians and domestic servants. A limited portion of professional/skilled positions were also opened mainly for the South Asians.

As the name denotes, the temporary economic migration is a time-bound, transient flow of migrants from outside the boundaries of a country. Due to its non-permanent nature, migrants have a general intention and plan to return to their place of origin after the assignment (Abella, 2006; Uriely, 1994). The GCC member countries offer opportunities for labour at various skill levels to address their labour needs, whist permanent immigration of foreigners is neither desired nor socially accepted in the GCC (Baldwin-Edwards, 2005).

A key component in temporary economic migration in the GCC member states is the kafala (sponsor) system. This sponsorship system, which has long-standing roots in the cultural traditions of the GCC region, (Babar and Gardner, 2016) provide short term contacts for the migrant workers, in most cases for twenty-four months. This system has come under severe criticism in the recent times, though some of the Gulf countries have made public arguments that any change to this kafala system would be detrimental to their economic competitiveness in the global arena (Gardner, 2010). Though many scholars and human rights organizations consider the kafala system to be an absolute 
deleterious mechanism, new research reveals that the migrants view this system also as a protective apparatus (Matsuo et al, 2020). Nonetheless, the issue of 'visa trading' or unofficially 'selling' the worker's visa to another sponsor has become a long term issue. (Al-Ubaydli, 2015) Hiring visa traded workers via the black market is attractive to sponsors as they can bypass recruitment fees and deny workers their full rights. (Al-Ubaydli, 2015; Shah, 2009) This kafala system is tied to labour sourcing through manpower agencies and agents. This is a vast profitmaking industry (Gardner, 2012) with profit distribution to all agents related to the recruitment process. However, criticism has been levelled at this process as it often forces migrants and their families to incur significant debts (IOM, 2019; Hoang, 2015) and their earnings are often used to cover these debts. This recruitment process has reciprocal causes and effects leading inexorably to a vicious circle, which promotes a circular pattern of migration.

The 'feminization' of the GCC migration corridor began with the GCC economic boom, with an estimated two million Asian women now working in this region (1). Women migrated mainly as reproductive occupations (2) such as domestic work in private households and informal commercial services (Piper, 2008; Yamanaka \& Piper, 2005). The Female Migrant Domestic Worker (FMDW) is a special group of migrant workers who migrate from their country of nationality to work in private homes in another country, performing various tasks such as cooking, cleaning, and caring for children or the elderly (Jayasuriya \& Opeskin, 2015). International Labour Organization (2013) estimates that sixty-three per cent of the 2.1 million domestic workers in the GCC are women and one in five of them are engaged in domestic work. This group drew considerable attention from researchers in the 1990s due to its size and the issued involved (Wickramasekara, 2002).

Sri Lankan migrant workers joined the workforce in the mid1980s (Rajan, 2016; Gunatilleke, 1986) with the laissez-faire economic reforms introduced in Sri Lanka from 1978. At present, GCC countries are the destination of choice for ninetyfour per cent of the Sri Lankan migrant workers (Siriwardene, 2015), among them, a significant portion of female migrant domestic workers (FMDW).

\section{IDEOLOGIES AND MODELS OF ECONOMIC MIGRATION}

Classical, Neo-Classical and Structuralist approaches predominate in discerning the social, economic and business factors behind human economic migration. The classic ideology of homo- economicus (economic man) is in the root of the ideologies of Classical and Neo-classical ideologies (Gardner, 2012). Classical ideology provides that human agents are constantly rational, narrowly self-interested and assesses optimally the end-results of his/her action (Zabieglik, 2002). This optimal end-result is the economic gain or the 'dollar-hunt', which could be fulfilled by migration. This ideology has been reinforced by the Rational Choice theory (Anisworth, 2019; Levin \& Milgrom, 2004). The neo-classical economic ideology premises how market functions are decided based on demand and supply cycle (Jones, 2012; Wiles, 1979). The same ideology can be applied to the labour market, as it determines the demand/ supply of labour and labour migration. The classic push, pull and mooring (PPM) is brought forth with this neo-classical migration ideology. The push and pull factors are linked to migrant workers home state and to the state of his/her destination respectively. The push factors such extreme poverty, political oppression, poor living standards and less economic opportunities etc. motivate an individual to migrate to another country voluntarily, and the pull factors such as higher wages, demand for labour, political and religious freedom, better education and economic opportunities etc. attracts these individuals to the countries of destination. The 'mooring factors' could be termed as the cost-benefit analysis of the migration decision. The push and pull factors do not work in isolation but interdependently with the mooring factors (O’Reilly, 2015).

Structuralists have presented the nature of modern industrial economies have created an environment for migrant labour. One structural explanation is the concept of 'dual labour markets' (Bentolila et al, 2019; Dickins \& Lang, 1985; Watcher, 1974; Poire, 1969) which assumes that labour markets in these labour receiving countries consist of two segments; the high-skilled labour sector and low-skilled worker sector. This concept assumes that migration from less developed countries into more developed countries is a result of a pull created by a need for labour in the developed countries in their secondary market, as the natives either do not have the capacity or do not want to perform these jobs. The GCC labour market is a classic example in this context. Another structural approach, the Worlds Systems theory, provides that migration is a natural outcome of the economic globalization (Hoffmann-Nowotny, 1989) and cultural globalization (Strikwerda, 2000). This has further developed into 'post-Structuralist culturalism' (Green, 1994). The 'new economics model' of migration underlines that migration as a decision made by families or groups (Stark, 1984) and the migration decisions are made of an analysis of plausible costbenefits. The push-pull factors are also being considered in this decision making. Contemporary approaches of migration is an admixture of above theories, models and examine that migration is a process that has more micro-level elements connected to larger macro-level factors connected to economic, social and political factors.

In the context of circular migration, ideologies such as 'cosmopolitanism', Nationalism and Cumulative causation has been brought forth. 'Cosmopolitanism' or the 'working-class cosmopolitanism' (Yeoh, 2013) is based on the ideologies of globalization and developmentalism, is the migrant's privileged access to social capital and economic muscle of the receiving state multiple times. The ideology of nationalism (Ishii et al, 2020; Babar \& Gardner 2016; Forstenlechner \& Rutledge, 2011) has been provided with two ends; first to 'balance the demography' as the foreign workers would shoulder a large portion of work, which otherwise has to be done by the nationals of the country, and second to provide the nationals in the GCC states, a supra status. This translates into the nationalist ideology of the states, where they consider the citizens of the country are the 'men of the soil'. The kafala system in place in the GCC is a classic example of this ideology, which is also a symbol of asymmetric power relation between the citizens and the migrants. The idea of cumulative causation (Massey, 1990), propounds that 
dynamic interplay of migrant remittances, local income distribution and network growth create a powerful feedback mechanism that sustains a cumulative causation for migrant for repeat migration.

Migration of Sri Lankans, especially the Female Migrant Domestic Workers (FMDWs) is a result of a combination of various factors highlighted in the above ideologies and no single theory could explain all the complexities involved (Ukwatte 2010; Karunaratne \& Abeygunawardene, 2018). Piper (2008) underlines that the pattern of migration of females needs to be looked at a 'gendered' point of view as patterns, as well as causes and consequences of the movements, are gender-specific. Gidden (1976) 's structuration approach has been referred to as a plausible base to examine gender and migration in Sri Lanka (Ukwatte, 2010; de Silva, 2006).

\section{ECONOMIC MIGRATION OF SRI LANKA}

Sri Lanka is a South Asian island nation, a home to some 21 million people (2018), which is located in the Indian Ocean, South-East of India. Having gained independence from the British Raj in 1948, the country made significant strides in human development and social development. Nevertheless, it is for a long time locked in the economic terms as a developing country and recently graduated to an upper-middle-income country (World Bank, 2018). In terms of human development, Sri Lanka has achieved a near-universal level of education at 96.3 percent (2018), with adult female literacy rate at 90.8 percent (UNESCO), which is the highest in South Asia. The social welfare programs of the governments since independence have positively contributed to a relatively high standard of living. Recent legislative changes have strengthened the rights of women including equality under the law, and in family matters, including marriage, divorce, child custody, and inheritance.

\section{Migration patterns of Sri Lanka}

Historically, four economic migration patterns could be observed in Sri Lanka. The first flow, to Malaysia, and occurred during the pre-Independence period. Soon after Independence in 1948, Sri Lankan groups migrated to Singapore and Hong Kong. They were predominantly middle-level skilled migrants and the numbers were minute. A large flow of migration occurred in the 1960s when professionals began to migrate to countries such as Australia, Canada and UK, permanently. This was mainly due to the demand for qualified labour in these countries as well as domestic instabilities arising from socio-economic strains. (Dias \& Jayasundara, 2004) The next major wave of economic migration occurred in the 1980s to the GCC countries which drew both skilled and unskilled male and female workers for short employment contracts, producing a pattern of circular migration (Gamburd, 2010; Ukwatte, 2005). In 2014 and 2015 Sri Lanka received US\$ 7,036 and 6.98 billion \$ respectively in remittances, which account for 8.4 percent of the GDP, well ahead of earnings from apparel ( $\$ 5$ billion), tourism ( $\$ 4.4$ billion) and agricultural exports (\$2.7bn) of which tea was $\$$ 1.5bn (Central Bank Report 2015). At present, migrant labour represents 23 per cent of Sri Lanka's total labour force (IPS, 2018).

This publication is licensed under Creative Commons Attribution CC BY

http://dx.doi.org/10.29322/IJSRP.10.10.2020.p10619
Feminization of migrants and the dominance of Female Migrant Domestic Workers of Sri Lanka

Internal and international mobilization of female labour is one of the outstanding features of the open economy (Ukwatte, 2010) introduce in 1978 to Sri Lanka. This paved the way to evolve the nature of the role of Sri Lankan women from a passive housewife to a breadwinner and provided more active roles in the economic markets (Kottegoda, 2006; Jayaweera, 1995). However, pervasive female unemployment coupled with perceived improvement in socio-economic status of women through economic migration, became a persuasive advertisement for women to migrate for work (Ukwatte, 2010). In the first two decades, starting from 1988, when the statistics are available, female migrant worker departures exceeded that of the males. In 1990, approximately three females departed for every male departure, making Sri Lanka one of the countries which had the highest female migration in the world (Frantz, 2014). Although the demand for Sri Lankan male workers declined in the mid1980s with the economic slowdown in the GCC countries, the departure of Female Migrant Workers increased further. These numbers later came closer to parity and in 2012, after more than two decades, male departures exceeded female departures for the first time.

\section{Graph 1- Female migration from Sri Lanka - 1986- 2018}

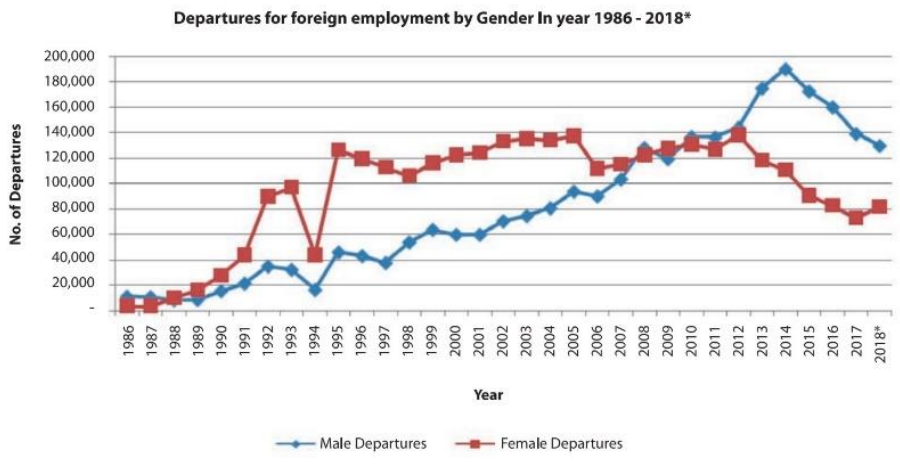

(Source-Sri Lanka Bureau of Foreign Employment)

Graph II - Female departures (Female Migrant Domestic Workers vs total Female Migrant Workers)

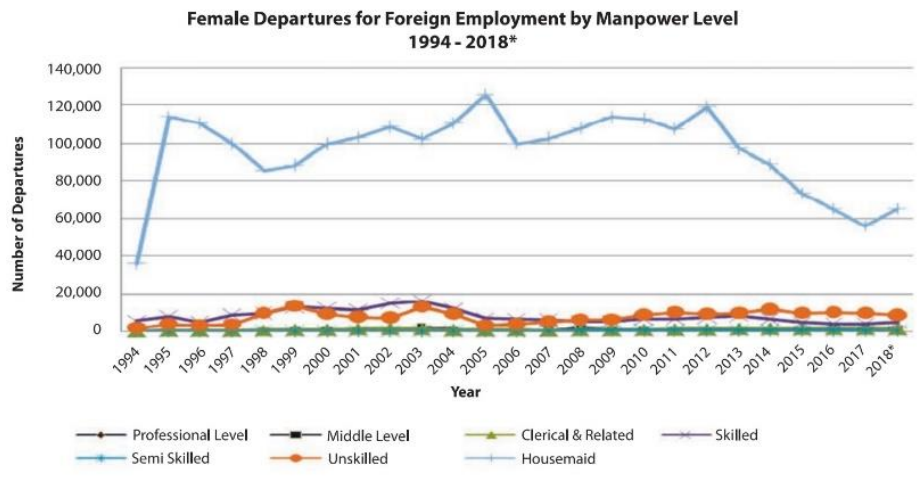

WwW.ijsrp.org 
(Source-Sri Lanka Bureau of Foreign Employment)

The percentage of Female Migrant Domestic Workers (FMDW) or housemaids, in common parlance, has fluctuated from $79-92$ percent from the total female migrations throughout the period. Typically, these Female FMDWs are aged between 35-45 years and educated to 6-10 grade. Some 70 percent of them are unemployed in Sri Lanka and 80 percent of them are married at the time of their departure. (Weeraratne, 2015; SLBFE, 2020). Financially, FMDW's are Sri Lanka's most successful export (Jayasuriya \& Opeskin, 2015; Ratha et al, 2014) and they contribute as the single largest export earnings (Kelegama, 2004).

\section{High demand for Sri Lankan Female Domestic Workers?}

From the vantage point of the GCC recruiters, several distinct features of the Sri Lankan FMDWs could be highlighted.

Price point: Compared to Filipino female migrant domestic workers, Sri Lankan FMDWs are considered to be an inexpensive option. The salary per month of a domestic worker is so low that they are affordable even for low-income level earning families in the GCC (In Saudi Arabia prior to the minimum wage was $\$ 120$ per month (pre-2000), \$173.50 (2000), \$ 200 (2012), \$ 240 (2013), and \$ 300 (2016 to date) compared to $\$ 400$ paid for a Filipino domestic worker). This is viewed as a major driver of demand though the comparatively high cost of initial recruiting a Sri Lankan FMDW, at approximately $\$ 3500$ to $\$ 4,750$ per person. (Weeraratne, 2020; Embassy of Sri Lanka Riyadh, 2019). Studies show that the prospective kafeels are prepared to spend a higher amount of money to recruit a Sri Lankan FMDW due to the social edge that Sri Lankan FMDWs brings forth over the others.

Social edge: Sri Lankan FMDWs has earned a reputation as loyal, obedient, hardworking, multitasking workers. Other particular features underlined are that they are 'clean', wellmannered and showing unwavering love for children (bringing up children as their children) (Sri Lanka Embassy Riyadh \& Kuwait, 2019). However, this notion of obedience and hard work have been interpreted as abuse by Ukwatte (2010), Dias \& Jayasundere (2004) and Eelens (1990).

\section{Peculiarities of Sri Lanka - GCC Female Domestic Worker Corridor}

Informal sub-agent culture: the recruitment of FMDWs in Sri Lanka involves sourcing through formal (licensed) recruitment agents and informal sub-agents. In this recruitment model, the most powerful player is the sub-agent, who is an informal entity operating at the grass-root level to mediate between the formal recruitment agent and the prospective FMDW. This subagent culture is common in South Asian countries, though India has banned this practice while in Nepal they are licensed through formal agents. The growth of subagent culture in Sri Lanka is mainly due to the increased demand for Sri Lankan FMDWs from the GCC.' Disreputable sub-agents mostly search for the uneducated, creating a 'deception trap' over salary levels, working hours and type of employment (Gardner, 2012). They further entice the prospective FMDW and her family with incentives and edited versions of the success stories of their previous clients. This sub-agent also assists the potential migrant to navigate the migration process. The bargaining power of subagents allows them to shop around different recruiting agencies and demand higher commissions for services (Weeraratne, 2018). Sub-agents are criticized for engaging in malpractice which leads to exploitative and abusive situations for migrants. However, it has been argued that formalizing the sub-agent model would lead to low wages and low incentives for the FMDW (Weeraratne, 2018; Pellizzari, 2010).

Upfront payment of incentives: In addition to absorbing the entire recruitment cost, paying a fee upfront is a unique practice which largely exits only in the Sri Lanka-GCC corridor, which is also a notable current development. At the beginning, this was provided only to Muslim Female Domestic Workers as a method to attract them to culturally similar families in the GCC (Weeraratne, 2020). In 2016, an FMDW who migrated to Saudi Arabia received an upfront incentive up to US \$1,000. This has subsequently decreased and by 2019 the incentive stood at $\$ 500$ for a novice first-timer and $\$ 800$ or more for an experienced FMDW with language expertise. This incentive payment has been criticized as a practice which can lead to debt bondage, making it difficult or impossible for a migrant worker to leave an abusive employer. It has also been observed that some of the FMDWs are absconding from the households of their employment, citing non-payment of wages during the initial months of employment. The main reason for this non-payment is the employers 'misunderstanding' that he/she has paid 3 moths of wages upfront to the domestic worker. There are instances of some FMDW working for 3-4 months and returning to Sri Lanka only to then proceed to another country to secure the upfront fee again. Upfront payment provides a drive for the circular migration of FMDWs. The United Nations Committee on the Migrant Workers and their Families (CMW) in its Sri Lanka country review in 2016 made a recommendation to 'abolish the practice of having to pay a motivational fee before leaving the State party... and consider adopting a no placement fee policy'(55 (e) CMW 2016).

Given that the 'total cost of migration' is being absorbed by the prospective sponsor, even the poorest of the Sri Lankan poor could leave as a FMDW, which is contrary to the generalized view provided by Tapinos (1990). This is an additional driver which often increases the FMDW's desire for migration.

\section{Circular Migration}

Though the term 'circular migration' or repeat migration first appeared in the late 1960s and 1970s. By the 1990s, the term was used to refer to international economic migrants in both developing and advanced industrial countries. The iterative dimension or the fluid pattern of back-and-forth cyclic repetitive movement of a migrant across borders is a distinguishing factor of circular migration from the return migration where a migrant 
makes only one roundtrip between the places of origin and destination. The migration pattern usually involves both return and repetition (Wickramasekara, 2002) and by definition, all circular migrations are temporary.

Academics have identified two main types of circular migration; spontaneous (voluntary) and managed. The spontaneous circular migration that occurs as a result of migrants' decisions, without government intervention (Newland, 2009). In the managed circular migration, governments seek to facilitate or instigate circular migration, intending to provide an alternative to unauthorized spontaneous migration (Newland, 2009). Circular economic migrants are generically referred to as 'guest workers' or 'temporary workers' and have no right to permanent settlement (Abella, 2006). This movement is viewed positively on the basis of accumulation of human and financial capital (Zimmermann, 2014; Cassarino, 2008; Wickramasekara, 2002).

\section{Decision tree of circular migration}

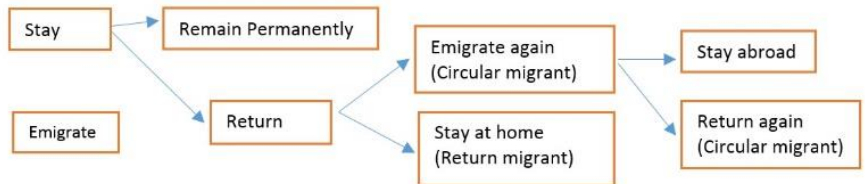

(Vadean and Piracha, 2009)

Though circular migration has become the attractive option for many migrants, it has been criticized for its impact on the families of the migrant workers and their communities. While comprehensive global data on circular migration does not exist (Jan \& Saarela 2019; Newland 2009), it is estimated that onethird of temporary economic migrants are circular migrants. In the GCC-Asian migration corridor, this comprises a quarter (Wickramasekara, 2013). India, Philippines, Bangladesh, Sri Lanka are identified as the main source countries (Newland, 2009). These workers are employed on fixed-term contracts ranging from one to three years and they re-migrate with new contracts for another similar short-term periods. (Wickramasekara 2013, 2002). Circular migration is one of the most visible migration patterns in the Sri Lanka - GCC migration corridor.

\section{Circular Migration OF SRi LanKan FMDWs}

It is estimated that a quarter of Sri Lankan FMDWs who are leaving from Sri Lanka are circular migrants (Wickramasekara, 2013). These female circular migrants are moving back and forth between the GCC multiple times during their adult working life. They start this journey in their mid-20s and return home periodically and, often, permanently when they reach their 40s and 50s, effectively spending almost two decades of their adult life in this migration cycle.

The pattern of 'step migration' where migrants leave the first destination not to return to Sri Lanka but to head to a second destination (Weeraratne, 2015), which could be noted in Sri Lankan male migration, is not prevalent among the FMDWs. The FMDW always returns to Sri Lanka before proceeding to another destination. The trend of 'hopping' to multiple destinations in their active working life is a key attribute of Sri Lankan circular FMDW as well. It has been observed that most first time FMDWs are moving to Kuwait and it remains their main choice for repeat migration. Saudi Arabia is their second choice and many FDWs who have served once in Kuwait move to Saudi Arabia. The UAE as a hotspot for FDWs is a recent trend, given the UAEs flexibility in converting tourist visas to work visas. The Sri Lankan government-mediated exclusionary policies, such as minimum age and Family Background Report, has reduced the number of FMDWs leaving the country for GCC with legitimate work visas. However, the flexibility of the visa regime in the UAE has enabled FMDWs to circumvent some of the State imposed barriers in the recent past.

A survey conducted in 2019 involving 100 FMDWs, in Saudi Arabia and Kuwait, historically the two main destinations for Sri Lankan housemaids (Weeraratne, 2014), postulating on the Push Pull and Mooring model (PPM) provides some of the insights to the reasons and motivations circular migration of Sri Lankan FMDWs. The FMDWs involved in this research belong to the age structure spanning from 28-45, which is the general age of the FMDWs (Weeraratne, 2014), are married and have children 10 years or older. The circular migration pattern and demographics of these FDMW are as follows:

Graphs III

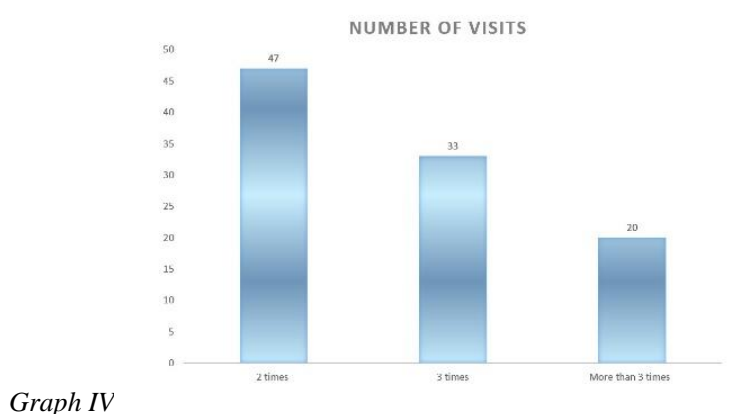

Graph IV 

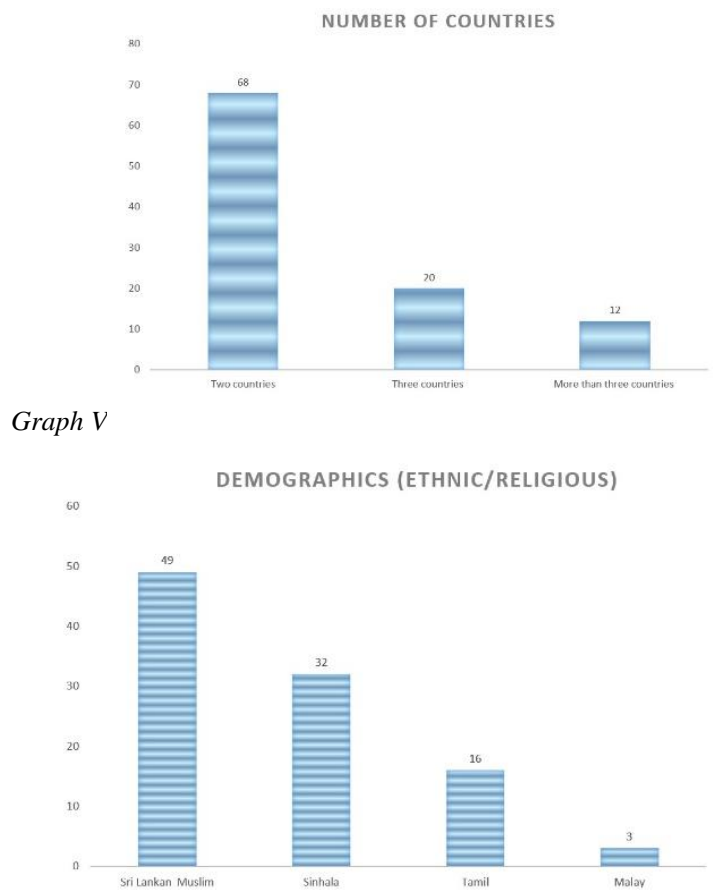

This entire cohort of FMDWs participated in the survey underlined that the primary reasons and motivation for their second departure were economic, with no other means available for them to support their families once they have returned from overseas. This concurs with Gardner (2016), Jayasuriya \& Openskin (2015), Ukwatte (2010), Kottegoda (2006) who underline that the cyclic pattern of migration occurs when there are no economic alternatives or opportunities for the migrant workers. Monetary gains which could be made in the migration process has become the main push factor for the FMDW's decision to leave the country. Monetary gains have invariably become the main pull factor as well. (Afsar, 2011; Athukorala, 1990). When deciding with both push and pull factors in play, the entire cohort of the group indicated they are more focused on the economic gain that they receive at the end of the tour of duty which is close to 300 percent higher than they get while in Sri Lanka. This concurs with Gardner (2016) that the circular migrant's analytic lens is principally focused on the end-result rather than the experience.

The main push factors of the Sri Lankan FMDWs, such as higher unemployment, unemployment of husbands and unavailability of economic opportunities (Ukwatte, 2010; Gamburd, 2005; Athukorala, 1990) apply to the circular migrants as well. Other main pull factors such as better country situation, entertainment, access to services, family links (Bandita, 2015; Jayasuriya \& Openskin, 2015; Piper, 2013; Rosewarne, 2012) and push factors such as natural disasters, social unrest (Bandita, 2015) have not been underlined by the FMDWs who took part in the survey, except for 3 percent of the FMDWs who cited the internal conflict in Sri Lanka as the reason to leave the country for the second time. The inhibitors of migration, such as policies governing emigration, immigration and border crossing (Czaika and De Haas, 2013) have also not been highlighted by the FMDWs who participated in this survey. Therefore, economic factor could be seen as the central premise and the only main pull and push factor for Sri Lanka- GCC FMDW circular migration corridor.

\section{Graph VI}

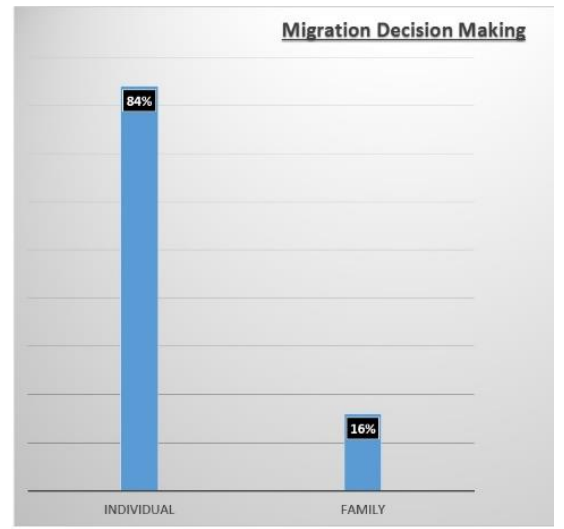

For eighty-four percent of the FMDWs who participated in this survey, the decision to leave the country for the second time or beyond has been an individual decision. The position of Gardner (2016, 2012); Massy et al (1998) and Stark (1991), that the decision to migrate to the Gulf is not often an isolated decision process, but a family decision, cannot be applied in toto to a circular migrant. It is apparent that the circular FMDW's agency is much higher than that of the first-timer and a circular FMDW takes this individual decision while considering a host of underlying extra-economic personal and social factors.

\section{FINDING THE 'OTHER': MOORING FACTORS}

There are complex underlying extra-economic reasons connected to the migrant's decision to migrate from the country for a second or subsequent time. These extra-economic reasons/mooring dynamics/ mediating drivers (Van Hear, 2018; Nyberg-Sørensen \& Van Hear, 2003) in migration literature were identified as personal (Lee, 1966) and social factors that impact decision of the migration, migration intentions and actions (Moon, 1995). These mooring factors enable, accelerate or diminish the migration decision. The migration decision is a complex interplay of both push and pull factors and moorings to arrive at the best decision taking into account the best options available (O'Reilly, 2015). The survey revealed the following mooring/mediating dynamics:

\section{Graph VII - Mooring factor in migration decision making}




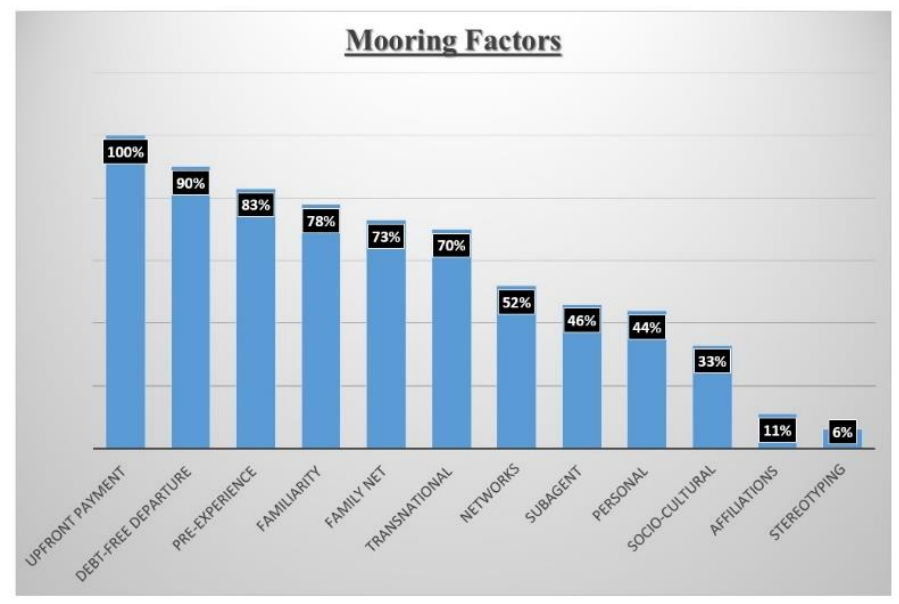

Upfront payment: The key mooring factor is the 'upfront payment' which is being received by the FMDW before her departure. As discussed earlier, this incentive for the FMDW is a major deciding factor to leave the country as well as instant relief from her immediate financial difficulties. The sub-agents who are scouting for prospective FMDWs are focusing on the FMDWs who have returned, as 'experienced' FDWs fetch a high price in the labour market. These FMDWs are offered higher 'upfront payment' as well as a higher monthly remuneration. This cannot be categorized at face value as a non-economic factor; however, the psychological catalyst that this would provide is more than an economic condition.

Debt free departure: The idea of debt-free departure is also an incentive as the total cost of the departure process is being taken care through the payment received from the prospective sponsor.

Previous experience: FMDW's choices and consequences of their past decisions and behaviour (Bakewell et al., 2016) coupled with the previous experience of their occupation also an important factor in the decision making process.

Familiarity with destination: Most of the circular migrant FMDWs have developed a bi-localized (Orsella, 2008) identity. In this process, FMDW learns to see the world through a 'double habitus', a set of impulses and unconscious motivations which is structured in both places. This bi-focality (Rouse, 1992) could be developed into a hybrid or fluid identity. Localization of cultural and religious markers could be observed in most of the FMDWs who participated in this survey.

Supportive family safety nets: A survey conducted in 2008 in Sri Lanka indicates that sixty nine per cent of the women had a relative to take care of their children. This cohort of FMDWs indicated that eighty two per cent of them left their children either with their mother or with the eldest daughter. Upon inquiry as to why not with a relative, the considered answer was that their relatives could not be trusted. Little mention was made on husbands who take care of children. The FMDWs who left their children were of the view that the education of these children improved as they could now afford tuition fees, books etc (3).

Trans-national relationships: Their ability to keep the 'transnational' relationships (Porters, 1996) and the 'transnational migration space' through regular phone calls, regular remittances and active participation in family decisionmaking at home also brought comfort to the circular migrants and thus an incentive to move with her job.
Personal networks: Most of the return migrants keep alive their informal personal networks (Horinuki, 2020; Bakewell et al., 2016), through social media and personal communication media such as Face Book, IMO and WhatsUp groups. In the GCC, migrant workers create subaltern networks while constantly checking the forms of networking that are permitted within the strict controls of the host governments. Ideas exchanged in these groups influence FMDWs decision-making. As revealed in the survey, almost all the survey participants are members of such trans-national networks from which they receive updates, guidance and support for their next expedition. These invisible and informal networks also offer migrants psychological and spiritual fulfilment as well.

Sub-agent rapport: The rapport with the recruitment sub-agent and the recruiting agency is another deciding factor. Information received from the migration agents is highly significant within this context. The FDMWs who undertook the survey indicated that sub-agents encouraged them to migrate and offered their support by providing necessary documentation and pre-departure preparations.

Personal Issues: These issues are explicitly connected to the family life of the FMDW back in Sri Lanka. The survey revealed that as much as sixty two per cent of the FMDWs returned to Sri Lanka after their first overseas vocation to find that their families were scattered, with husbands abandoning them and moving with other partners. Such women have no other way of survival or motive to stay home and so leave again as FMDWs. Harrowing tales of abusive or dysfunctional relationships were prevalent. For them, circular migration is an effective escape mechanism.

Socio-cultural issues: These entails caste, race and religious practices prevalent in the rural areas in Sri Lanka, where most of the FMDWs hail from. A pertinent issue highlighted by the FMDWs is the implicit taboo in the Sri Lankan Muslim society for women employed as domestic aids, though there is no such reservation when they go abroad as FMDWs. This is on the premises of purported affinity of the Muslim society with the GCC countries. Thirty per cent of FDWs who are of the Islam faith provided that the 'religion' is a major determinant in returning to Saudi Arabia.

Personal affiliations: Survey also revealed that some of the FMDWs have been able to establish connections with men of the same nationality or from other nationalities. These cross border affiliations have also prompted the FMDWs decision to return to the Gulf.

Negative stereotyping: Social stigma restricts opportunities for the FMDWs to find other employment or affinities once they are back in Sri Lanka. The idiomization of FMDWs with lurid sobriquet 'foreign whores' has increasingly left the FDWs with a myriad of social issues and abuses in their social strata. This negative stereotyping could be identified as a trigger as well as a mooring factor.

The above opinions expressed by the FMDWs surmises the gamut of interrelated powerful mooring factors, which drives the FMDWs to shape her opinion to make a second move to go overseas.

\section{OTHER OBSERVATIONS}

This survey also underlines the failure of managing the return migration in Sri Lanka. Though return migration has been called 
the least understood aspect of the migration process (Hall 2017), much focus was given to this aspect in Sri Lanka (ILO, 2015; Collyer et al, 1999; Athukorala,1990). Structuralist ideology underlines that return returnees, once they arrive, tend to orient their savings in unproductive investments and conspicuous consumptions due to their need to be "'reaccepted" into society (Cassarino, 2004). This is not completely analogous with the Sri Lankan FMDWs. In most cases, women migrants find very little of their earnings remaining as savings or investment as their family members have used these remittances only for consumption (Kottegoda, 2006). The resultant cumulative causation (Massey et al, 1990) makes the migrant worker's subsequent migration inevitable. Though the Government of Sri Lanka, international organizations such as IOM and other NGOs are placing their focus on educating the FMDWs to manage the return migration, the survey indicated that sixty per cent of the FMDWs are uninformed and unorganized about their return. It was also revealed that ninety per cent of the FMDWs started to "spare some money" for themselves only at the second round of migration circle. This survey revealed that thirty per cent of the second timers and seventy per cent of third timers intended to return to the GCC, which indicates a habitualization of their act, (Cohen \& Jónsson, 2011) forming a 'culture of migration'. The survey participants also indicated that their agency is strongly enabled and minimally constrained by structural conditions imposed by an individual's social relations.

This Survey reconfirms that these FMDWs assumed the same domestic chores that they used to carry out before their departure, but with added sophistication. They have not acquired any additional 'employable skill' (4). Therefore the widely held idea of using the skilled acquired aboard in the country of origin is not quite applicable to the return FDMWs. Almost all the FMDWs in the survey accepted that they have "no skill to do any other job' other than day to day household chores. They had no intention of diverting to other employment options such as employment in Free Trade Zones which is a common option available to unemployed females in Sri Lanka.

\section{POSSIBLE TRAJECTORIES OF FUTURE FMDWS}

Whilst shifting from the migration policy of the '80s and '90s, at present, the Government of Sri Lanka emphatically and overtly discourages women leaving as FMDWs (5). The implementation of obtaining Family Background Report (FBR), a clearance certificate for FMDWs which came into effect on 15th July 2013 effectively bans women with children under the age of five from migrating overseas. However, this circular has been challenged by various quarters and in October 2016, the UN Committee on Migrant Workers and their families (CMW) in its concluding observations recommended that the State party withdraw this circular $(25(\mathrm{e}))$

Except for Saudi Arabia (6), these restrictions have not totally discouraged the FMDWs from leaving the country which presents a paradoxical situation. The government's strong aversion towards FMDWs leaving for the GCC corridor has effectively made women search for other alternative departure methods, including through tourist visa, to circumvent the imposed movement restrictions. The government has not placed a strict imposition barring females leaving the country, mainly owing to the pressure emanating from the Labour recruitment agencies.

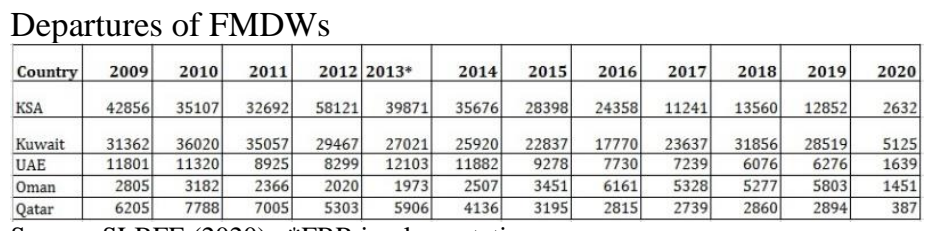

Source: SLBFE (2020) *FBR implementation

At present, the Government of Sri Lanka has adopted a new policy of destination diversification by adding new 'maleoriented' markets such as South Korea, Japan and East European countries and explicitly encourages male workers to leave overseas for skilled work. The main intention of this process is to increase the remittance flows to Sri Lanka by complimenting and countervailing the dip in remittances generated by the FMDWs (SLBFE, 2018). However, the validity of this remittance maximization model has been called to question. Weeraratne (2020) provides that the dip in the remittances since 2015 owes to the decrease in the number of housemaids as well as the increase of skilled male workers, who remit less. The above survey data is also commensurate with the findings that FMDWs are remitting steadily in larger percentages (Le Goff, 2016). However, males who are doing unskilled jobs tend to remit high amounts if they receive a high salary (Karunaratne \& Abeygunawardana, 2018) while skilled \& professional migrants are remitting less to their home country. If the government of Sri Lanka wants to effectively use the remittance increase model, then they have either to expand the unskilled-high earning sector and skilled workers by a minimum of fifty per cent to substitute the FMDW earnings. The GCC recruiters are of the view that Sri Lanka cannot provide the sufficient numbers and the skill levels of male workers that they seek (7). The Arabization and 'nationalization' processes of the destination countries in the aftermath of COVID-19 pandemic have also cut down both skilled/unskilled male recruitments, but interestingly, this has not affected the domestic sector. Therefore, it is doubtful that the new remittance maximization model of Sri Lanka would work out as it deems to be.

At present, the Government of Sri Lanka faces a dilemma. On one hand, it increasingly desires the remittances provided predominantly by the FMDWs, on the other hand, they have faced challenges in expanding male migrant workers as well as encouraging them to remit more. This leaves the Government with no choice but to allow the neoliberal globalized economic conditions to dictate the terms of migration. Though circular migration is not a panacea, the current circular migration trends are certainly suited to contemporary circumstances.

Given the fact that issues such as the female poverty and structural anomalies of reintegration are yet to be addressed, the circular migration of the FMDWs to the GCC will continue, or perhaps thrive in the current post- COVID 19 situation. 


\section{END NOTES}

1. This is defined as rising number of independently migrating women in the migration streams (Piper, 2005:5)

2. The term 'reproductive' work refers to those activities related to (a) human reproduction and (b) maintaining and sustaining human beings throughout their life cycle (Truong, 1996:32).

3. Most of the FMDWs experience breakdowns in their marriages when they return. Lack of interest for education, poor and wrong leadership and low educational performance are common among the migrant worker's children, including mental and behavioral problems (Ukwatte, 2010)

4 For males it is mainly 'de-skilling' as they do menial jobs. (Athukorala, 1990)

5. Consideration of reports submitted by States parties under article 73 of the Convention pursuant to the simplified reporting procedure Second periodic reports of States parties due in 2011 (October 2016)

6. The reductions in mainly visible in Saudi Arabia, and is mainly owing to the negative publicity generated through the execution of an underage domestic worker Rizana Nafeeq in 2012 and opening some markets like Bangladesh and African countries to source domestic workers. Kuwait's flexible visa and labour regime has also become a major pull factor.

7. Author's discussion with the Mega Recruitment Companies in Saudi Arabia revealed that Sri Lanka cannot provided the numbers in categories of skills that they are needed. (December, 2019)

\section{ACKNOWLEDGMENT}

The author acknowledges the comments made by Julie O'brian (University Collage - Dublin) and Jayathry Gunaratne (Ehwa University - Seoul) on an early draft of this paper.

\section{ETHICS}

The FMDWs who participated in this survey were ensured confidentiality and received oral and written information about the study topic, aim and procedures, voluntary participation, and their right to withdraw at any time. The interviews were conducted in privacy.

\section{REFERENCES}

[1] Afsar, R. (2011). Contextualizing Gender and Migration in South Asia: Critical Insights. Asian Institute of Technology, 15(3),389-410

[2] Ainsworth, S. (2019). Rational Choice Theory Overview, Monograph, University of Georgia

[3] Albella, M. (2006). Policies and Best Practices for Management of Temporary Migration. International Symposium on International Migration and Development, Turin.

[4] Al-Ubaydli, O. (2015). The Economics of Migrant Workers in the GCC. Issue paper 10. Washington D.C: Arab Gulf States Institute in Washington.
[5] Athukorala, P. (1990). International Contract Migration and the Reintegration of Return Migrants, The Experience of Sri Lanka, International Migration Review, 24(2). 323-346

[6] Babar, Z., \& Gardner, A. (2016). In C, Sole (Ed.). Circular Migration and the Gulf States Impact of Circular Migration on Human, Political and Civil Rights (pp. 45-62). New York: Springer

[7] Bakewell, O. (2016). Feedback in Migration Processes. In O, Bakewell, G, Engbersen, M. L, Fonseca \& C, Horst (Eds.). Beyond Networks: Feedback in International Migration (pp. 1-17).Basingstoke: Palgrave,

[8] Baldwin-Edwards, A. (2005). Migration in the Middle East and Mediterranean. Geneva: Global Commission for Migration

[9] Bandita, S. (2015). Women Labour Migration from Asia and Pacific: Opportunities and Challenges. Geneva: IOM

[10] Bentolila, S., Dolado, J.J. \& Jimeno, J.F. (2019). Duel Labour Markets Revisited. CESifo Working Paper no. 7479. Bonn: Center for Economic Studies

[11] Bogue, D. J., (1977). A Migrants-Eye View of the Costs and Benefits of Migration to a Metropolis. In A. A. Brown and E. Neuberger (Eds.). Internal Migration: A Comparative Perspective (pp. 167-182). New York: Academic Press.

[12] Cassarino, J. A. (2004). Theorizing return migration: A revisited conceptual approach to return Migrants. International Journal on Multicultural Societies, 6 (2), 253-279

[13] Cassarino, J.A. (2008). The Conditions of Modern Return Migrants Editorial Introduction. International Journal on Multicultural Societies, 10 95-105

[14] Cohen, R. \& Jónsson, G. (2011). Introduction: Connecting Culture and Migration. In R, Cohen and G, Jónsson (Eds.) Migration and Culture. Cheltenham: Edward Elgar

[15] Collyer, M, Ansar, N., Khan, M.A. (2009). Return Migrants in Sri Lanka. London: Institute for Public Policy Reserch

[16] Czaika, M. \& De Haas, H. (2013). The effectiveness of Immigration policies. Population and development review 39 (3), 487-508

[17] De Silva, I. \& Siriwardene, D. (2015). Increasing family disputes and divorce in modern Sri Lanka: is labour migration a key contributor? Conference Paper, Swedish South Asian Network (SUNSET) conference. Lund

[18] de Silva. N, (2006). Female migration: gender and class restructuration. Stockholm: Stockholm University

[19] Dias, M. \& Jayasindara, R, (2004). Sri Lanka: Good Practices to prevent women migrant workers from going into exploitive forms of labour. Women on migration, Gender promotion program, GENPROM Working paper No 9. ILO: Geneva

[20] Dickens, W., \& Lang, K. (1985). A Test of Dual Labor Market Theory. The American Economic Review, 75(4), 792-805

[21] Elens, F. \& Speckmann, J.D. (1990). 'Recruitment of Labour Migrants for the Middle East: The Sri Lanka case. International migration review, 24(2), 297-322

[22] Forstenlechner, I. \& Rutledge, E. J. (2011). The GCC's demographic imbalance perceptions, realities and policy options. Middle East Policy, 28 (4), 32-33.

[23] Frantz, E. (2014). Breaking the isolation: information and media among migrant domestic workers in Jordan and Lebanon. New York: Open Society Foundations

[24] Gamburd, M. R. 2000. The Kitchen Spoon's Handle: Transnationalism and Sri Lanka's Migrant, Housemaids. Ithaca, NY: Cornell University Press.

[25] Gardner, A. (2012). Why Do They Keep Coming? Labor Migrants in the Gulf States. In M, Kamrava \& Z, Babar (Eds.) Migrant Labour in the Persian Gulf. New York: Columbia University Press

[26] Green, N.L. (1994). The Comparative Method and Post-structural Structuralism: New Perspectives for Migration Studies, Journal of American Ethnic History, 13(4), 3-22

[27] Gunatilleke, G. (1986). Sri Lanka, Migration of Asian Workers to the Arab World. Tokyo: UNU

[28] Hall, S. (2017). Setting standards for an integrated approach to reintegration: a summary report of Mediterranean Sustainable Reintegration. Geneva: IOM

[29] Hussain, Z. (2016). GCC's immigration policy in the post-1990s: contextualising South Asian migration. In P.C, Jain \& G. Z, Oommen 
(Eds.). South Asian Migration to Gulf Countries: History, Policies, Development (pp. 93-121). London: Routledge

[30] ILO (2013). Domestic Workers Across The World: Global And Regional Statistics And The Extent Of Legal Protection no 08. Geneva: ILO

[31] Ishii, M., Hosoda, N., Matsuo, M. \& Horinuki, K. (2020). Asian migrant workers in the Arab gulf States. Leiden:Brill.

[32] Jayasuriya, R. \& Openskin, B. (2015). The Migration of Women Domestic Workers from Sri Lanka: Protecting the Rights of Children Left Behind. Cornell International Law Journal, 48, 583-638

[33] Jayaweera, S. (1995). Introduction. In Facets of Change of Women in Sri Lanka 1986-1995, (pp. 1-5). Colombo: Center for Women's Reserch

[34] Jonathan, L \& Milgrom, P. (2004). Introduction to Choice Theory. Monograph. Stanford University.

[35] Jones, D. S. (2012). Masters of the Universe: Hayek, Friedman, and the birth of neoliberal politics. Princeton: Princeton University Press

[36] Kapiszewski, A. (2006). Paper presented at United Nations Expert Group Meeting on International Migration and Development in the Arab Region Population Division Department of Economic and Social Affairs United Nations Secretariat Beirut.

[37] Karunaratne, H. D. \& Abeygunawardana, K. (2018). Reintegration of Sri Lankan Returnee Migrant Workers from South Korea, Hosei University Departmental Bulletin Paper, 85 (3), 65 - 94

[38] Kelegama, S. (2004). Economic Policy In Sri Lanka: Issues And Debates. New Delhi: SAGE

[39] Kottegoda, S. (2006). 'Bringing Home the Money: Migration and Poverty in Gender Politics in Sri Lanka'. In S. Arya and A. Roy (Eds.). Poverty, Gender and Migration, Women and Migration in Asia (Vol. 2)(pp. 49-71). New Delhi: SAGE

[40] Lee, E. S., (1966). A Theory of Migration. Demography, 3 (1), 47-57.

[41] Le Goff, M. (2016). Feminization of migration and trends in remittances. Bonn, Germany: IZA World of Labor, Institute for the Study of Labor.

[42] Moon, B. (1995). Paradigm in Migration Research: Exploring 'Moorings' as a Schema. Progress in Human Geography, 19, 504-524.

[43] Nyberg-Sørensen, N \& Van Hear, N. (2003). The Migration-Development Nexus: Evidence and Policy Options. International Migration, 40 (5), 49-73

[44] Newland, K. (2009). Circular Migration and Human Development, $\mathrm{NY}: \mathrm{UNDP}$

[45] O'Reilly, K. (2015). Migration Theories: A Critical Overview. In A. Triandafyllidou (Ed.) Routledge Handbook of Immigration and Refugee Studies (pp. 25-33). Abingdon, Oxford: Routledge

[46] Pellizzari, M. (2011). The use of welfare by migrants in Italy. Bonn: Institute for the Study of Labor (IZA)

[47] Piore, M,J. (1969). On-the-job training in the dual labor market: public and private responsibilities. In C. Weber \& M. Ginsburg, On the-job training of disadvantaged workers in public-private manpower policies (pp. 101-132). Wisconsin: Industrial Relations Research Association

[48] Piper, N. (2008). Feminisation of Migration and the Social Dimensions of Development: The Asian Case, Third World Quarterly, 29(7), 1287-1303

[49] Piper, N. \& Lee, S. (2013). Contributions of Migrant Domestic Workers to sustainable Development, Policy Report prepared for UN Women Regional Office for Asia and the Pacific. Bangkok: UNWOMEN

[50] Piper, N. (2013). Gendering the politics of migration. The International Migration Review, 40(1), 133-164

[51] Rajan, I. (2016). South Asia Migration Report 2017: Recruitment, Remittances and Reintegration. London: Routledge India

[52] Ratha, D. (2014). Migration and Remittances: recent developments and outlook. Washington D.C.: World Bank

[53] Rosewarne, S. (2012), Temporary International Labor Migration and Development in South and Southeast Asia, Feminist Economics, 18(2), 6390

[54] Rouse, R. (1992). Making Sense of Settlement: Class Transformation, Cultural Struggle and Transnationalism among Mexican Migrants in the United States, In N. Glick Schiller, L.Basch, \& C. Blanc-Szanton (Eds.), Towards a Transnational Perspective on Migration, (pp. 25-52), New York: New York Academy of Sciences.

[55] Shah, N. (2009). The Management of Irregular Migration and its Consequence for Development: Gulf Cooperation Council, ILO Asian
Regional Programme on Governance of Labour Migration Working Paper 19. Geneva: ILO

[56] Siriwardene, D. (2015). Sri Lanka-Middle East Labour Migration Corridor: Trends, Patterns and Structural Changes. International Journal of Social, Behavioural, Educational, Economic and Management Engineering, 8 (12), $3863-3866$

[57] Stark, O. (1991). The Migration of Labor. Oxford: Blackwell.

[58] Strikwerda, C. (2000). From World-Systems to Globalization: Theories of Transnational Change and the Place of the United States, American Studies, $41,(2 / 3), 333-348$

[59] Tapinos, G. P. (1990.) Development Assistance Strategies and Emigration Pressure in Europe and Africa. Washington DC: Commission for the Study of International Migration and Co-operative Economic Development

[60] Truong, T. (1996). Gender, international migration and social reproduction: Implications for theory, policy research and networking. Asian and Pacific Migration Journal, 5 (1), 27-52.

[61] Ukwatte, S. (2005). Internal Migration of Women and Development in Asia. In Migration Development and Poverty Reduction in Asia, (pp. 181194), Geneva: IOM

[62] Ukwatte, S. (2010). Economic and Social Impacts of the Migration of Sri Lankan transnational domestic workers on families and children left behind. Unpublished PHD thesis, University of Adelaide.

[63] Uriely, N. (1994). Rhetorical ethnicity of permanent sojourners: the case of Israeli immigrants in the Chicago area. International Sociology, 9 (4), 431445

[64] Vadean, F. \& Piracha, M. (2009). Circular migration or permanent return: What determines different forms of migration?. Discussion Paper No. 4287. Bonn: Institute for the Study of Labor (IZA)

[65] Van Hear, N. (2018). Push-pull plus: reconsidering the drivers of migration. Journal of Ethnic and Migration Studies, 44(1),1-18

[66] Wachter, M.L. (1974). Primary and secondary markets: a critique of the dual approach. Brooklyn papers on Economic activity, 3, 637- 693

[67] Webber. R. \& Saarela, J. (2019). Circular migration in a context of free mobility: Evidence from linked population register data from Finland and Sweden. Population Space and Place, 25(4), 1-12

[68] Weeraratne, B. (2014). Sri Lankan Female Domestic Workers in the Middle East. Labour Economic Series no. 18. Colombo: IPS

[69] Weeraratne, B. (2018a). Tracing informal recruitment relationships through a panel survey of migrants. Presentation at the International forum on migration statistics. January 15-16, Paris

[70] Weeraratne, B. (2018b). Migration and Gender Outcomes: Analysis of Selected Policies in Sri Lanka. KNOMAD Working Paper, Washington D.C: World Bank

[71] Weeraratne, B. (2020). Labour Migration from Sri Lanka to the Gulf: Current Status and Future Outlook. In I. Rajan \& G. Z. Oommen (Eds.) Asianization of Migrant Workers in the Gulf Countries (pp. 219-231). New York: Springer

[72] Wickramasekera, P. (2002). Asian Labour Migration: issues and challenges in an era of globalization. International Migration papers no 57. ILO: Geneva

[73] Wickramasekara, P. (2013). Circular and Temporary Migration Regimes and their Implications for Family. Qatar: Qscience Proceesings.

[74] Wiles, P. (1979). Ideology, Methodology, and Neoclassical Economics. Journal of Post Keynesian Economics, 2(2), 155-180

[75] World Bank (2018). Sri Lanka Development Update, June 2018: More and Better Jobs for an Upper Middle-Income Country. Washington DC: World Bank.

[76] Yamanaka, K. \& Piper, N. (2005). Feminized Migration in East and Southeast Asia: Policies, Actions and Empowerment. Geneva: United Nations Research Institute for Social Development

[77] Yeoh, B. (2013). 'Upwards' or 'Sideways' cosmopolitanism? Talentlabour-marriage migrations in the globalizing city-state of Singapore. Migration Studies, 1(1), 96-116

[78] Zabieglik, S. (2002). The origins of the term homo-economicus. In J. Kubka (Ed.) Economics and Values (pp. 123-130). Gdansk: Gdańsk University of Technology 


\section{AUTHOR}

Author - Madhuka Sanjaya Wickramarachchi, (M.Phil), Ministry of Foreign Affairs- Sri Lanka, madhukaw@gmail.com 